\title{
Cervical carcinoma metastasizing to uveal tissue manifesting as pseudohypopyon
}

\begin{abstract}
The metastasis to the eye in a patient of carcinoma of the cervix is rare. A case of carcinoma cervix in a 56-year-old female is described who presented with full chamber pseudohypopyon and deep vascularization in inferior quadrant of the cornea in the left eye. Magnetic resonance imaging revealed features suggestive of ocular metastasis in the anterior part of the uveal tract. Diagnosis was confirmed on cytology which showed features of squamous cell carcinoma. A high level of clinical suspicion in advanced cases of malignancies will help in early detection of ocular metastasis with unusual presentations.
\end{abstract}

Keywords: Carcinoma of cervix, pseudohypopyon, uveal metastasis

\section{INTRODUCTION}

Cervical cancer is the fourth most common malignancy in women worldwide, and it remains a leading cause of cancer-related death for women in developing countries. ${ }^{[1]}$ Uveal metastasis has been documented from different sites and the common being breast and lungs. On review of literature, there are five reported cases of uveal metastasis from cervical carcinoma and none presented with psuedohypopyon.

\section{CASE REPORT}

We report a case of 56-year-old Female diagnosed in November 2013 with moderately differentiated squamous cell carcinoma of the cervix Stage II B. Chemoradiotherapy 6 cycles at chemotherapy (cisplatin $50 \mathrm{mg}$ i.v weekly) and local radiotherapy ( 46 gray $/ 4 \frac{1}{2} \mathrm{wk} / 23$ fractions) were administered in November 2013. In May 2014, the patient reported retention of urine. Computed tomography (CT) abdomen and pelvic showed bulky cervix with inhomogeneous enlargement. On contrast CT, there were enlarged lymph nodes measuring $32 \mathrm{~mm}$ x $25 \mathrm{~mm}$ in the left para aortic area, which enhanced heterogeneously. In view of local relapse in the cervix, the patient was started palliative chemotherapy based of cisplatin and 5-fluorouracil for six cycles, last cycle in November 2014.

\begin{tabular}{|c|c|}
\hline \multicolumn{2}{|c|}{ Access this article online } \\
\hline & Quick Response Code \\
\hline $\begin{array}{l}\text { Website: } \\
\text { www.asjo.in }\end{array}$ & 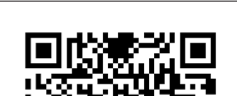 \\
\hline DOI: & 375 \\
\hline 10.4103/ASJO.ASJO_36_17 & ? \\
\hline
\end{tabular}

In February 2015, the patient presented in eye outpatient department with a complaint of loss of vision left eye associated with pain for the past 2 months. The patient had 6/6 vision in the right eye on Snellen's chart. Anterior and posterior segment examination was within normal limits in the right eye. In the left eye, the patient had no light perception. On slit-lamp examination, deep and superficial conjunctival congestion with mild chemosis in the inferior quadrant was present, and there was deep vascularization in the inferior quadrant of the cornea extending from 5 to 7 o'clock infiltrating 3-4 mm of the cornea. Anterior chamber was full of whitish exudates covering whole of the pupil and more than two-thirds of the iris with hyphema in the inferior quadrant [Figures 1 and 2]. Due to media haze Grade IV, lens and fundus details could not be visualized. Intraocular pressure was 14 and $28 \mathrm{mmHg}$ in the right and left eye, respectively.

\section{Vinay Gupta, Vinod Sharma, Kalpana Sharma, Deepti Parmar}

Department of Ophthalmology, Indira Gandhi Medical College, Shimla, Himachal Pradesh, India

Address for correspondence: Dr. Vinod Sharma, Department of Ophthalmology, Indira Gandhi Medical College, Shimla, Himachal Pradesh, India.

E-mail: drsharma.track@gmail.com

This is an open access article distributed under the terms of the Creative Commons Attribution-NonCommercial-ShareAlike 3.0 License, which allows others to remix, tweak, and build upon the work non-commercially, as long as the author is credited and the new creations are licensed under the identical terms.

For reprints contact: reprints@medknow.com

How to cite this article: Gupta V, Sharma V, Sharma K, Parmar D. Cervical carcinoma metastasizing to uveal tissue manifesting as pseudohypopyon. Asian J Oncol 2017;3:147-50. 
B-scan left eye showed hyperechoic shadows of $40 \%-50 \%$ reflectivity in vitreous with posterior vitreous detachment [Figure 3]. Magnetic resonance imaging demonstrated thickening of the anterior portion of the uveal tract [Figure 4] with no secondaries/lesion in the brain. Possibility of ocular metastasis or metastatic endophthalmitis was kept. Aqueous and vitreous tap was done with intravitreal antibiotic injections (vancomycin $1 \mathrm{mg}$ in $0.1 \mathrm{ml}$ and ceftazidime $2.25 \mathrm{mg}$ in $0.1 \mathrm{ml}$ ). The samples were sent for Gram staining, potassium hydroxide mount, culture sensitivity, and cytology. Microbiology results were negative, and cytology showed cellular smears comprised of aggregates of pleomorphic tumor cells having hyperchromatic, angulated, and focally pyknotic nuclei with coarse chromatin, with inconspicuous nucleoli and basophilic cytoplasm suggestive of squamous cell carcinoma [Figure 5]. The patient was advised enucleation for painful blind eye and was sent to the radiotherapy department

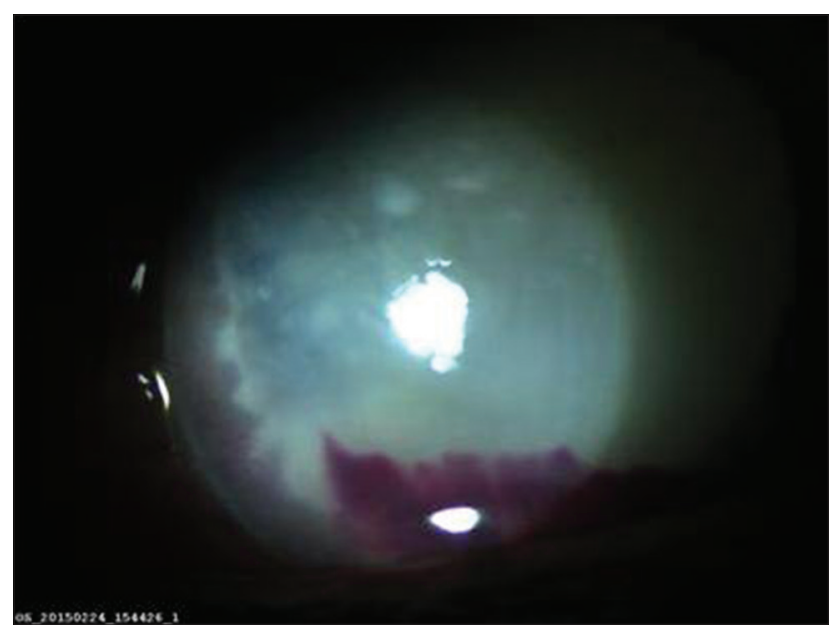

Figure 1: Slit-lamp photograph left eye showing whitish exudates (pseudohypopyon) covering whole of the anterior chamber except some portion of the iris

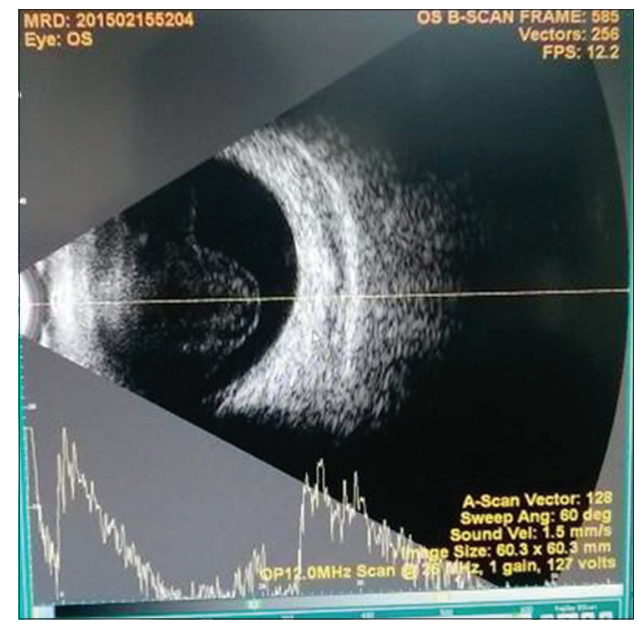

Figure 3: B-scan left eye showing hyperechoic shadows of $40 \%-50 \%$ reflectivity suggestive of exudates in vitreous and posterior vitreous detachment for further management. On PS/PV examination, the patient had locally progressive ulceroinfiltrative growth of the cervix extending to the introitus. Contrast-enhanced CT showed extension of carcinoma to lower uterine segment and multiple lymph nodes in parametrium and pelvic with metastasis in D11, D12, and L3 vertebrae. In view of painful blind eye and absence of brain metastasis, enucleation was done and sent for histopathological examination (HPE). On HPE, squamous cell carcinoma metastasis was found in the ciliary body which invaded subretinal space between choroid and retina [Figures 6 and 7]. As the patient had already received extensive treatment, prognosis was explained to attendants/patient, and the patient was put on best supportive treatment. The last follow-up was on September 27, 2015.

\section{DISCUSSION}

Ocular metastasis in case of carcinomas is a rare manifestation. The incidence of metastatic carcinoma to the eye varies by

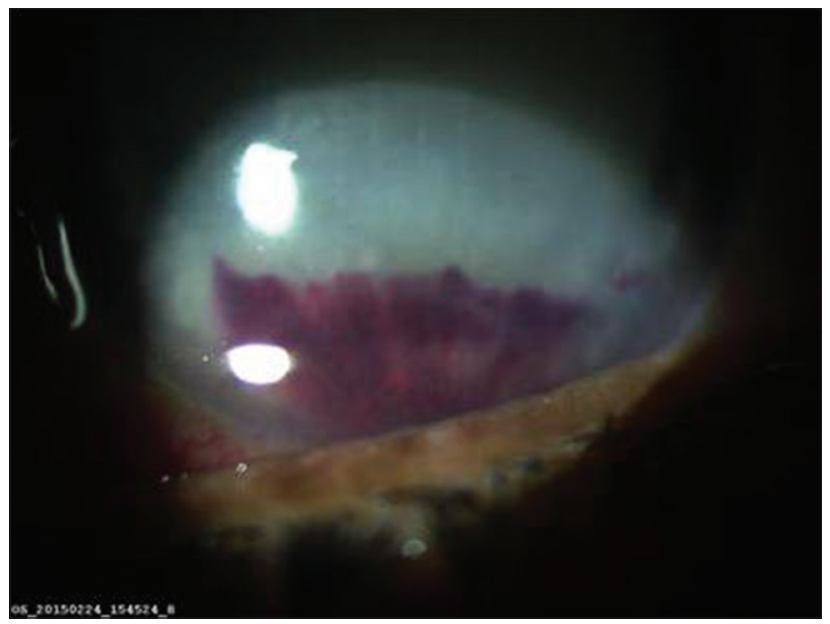

Figure 2: Slit-lamp photograph left eye showing deep vascularization in the inferior quadrant along with hyphema and full chamber pseudohypopyon

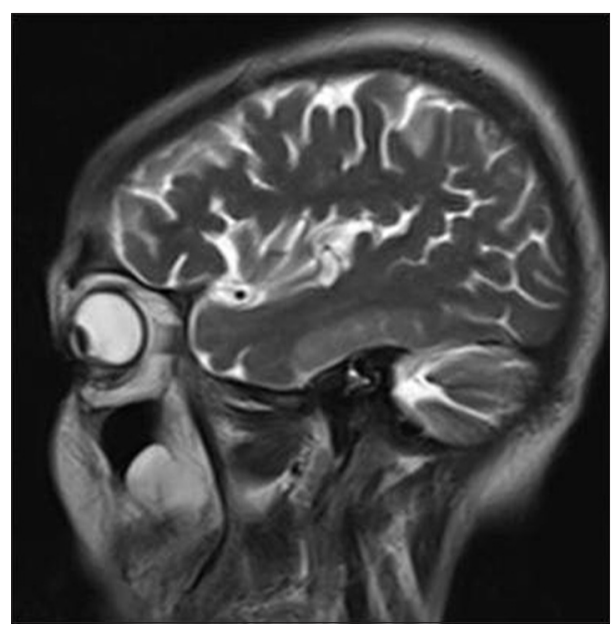

Figure 4: Magnetic resonance imaging T2-weighted sagittal image showing thickening of uveal tissue more marked in the anterior portion of the uvea 


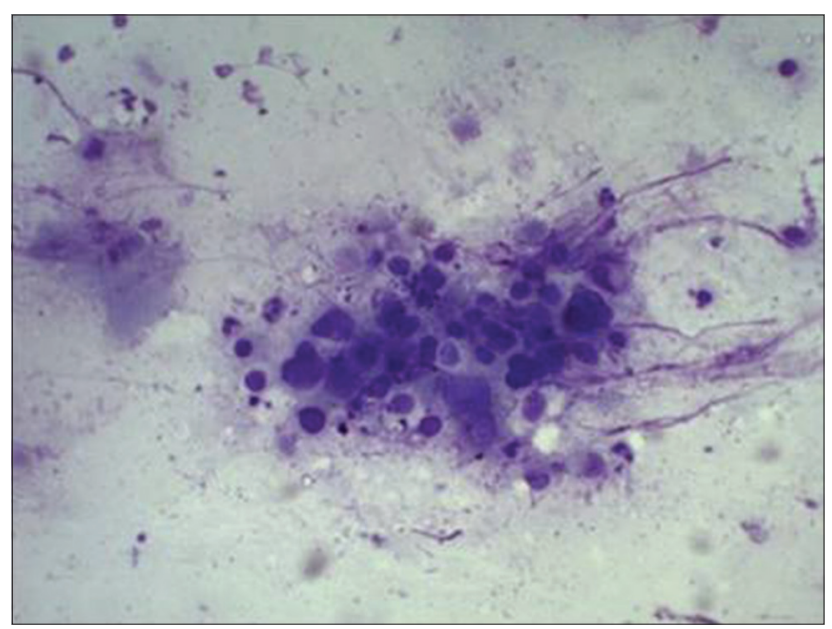

Figure 5: Cytology of aqueous tap showing features of squamous cell carcinoma

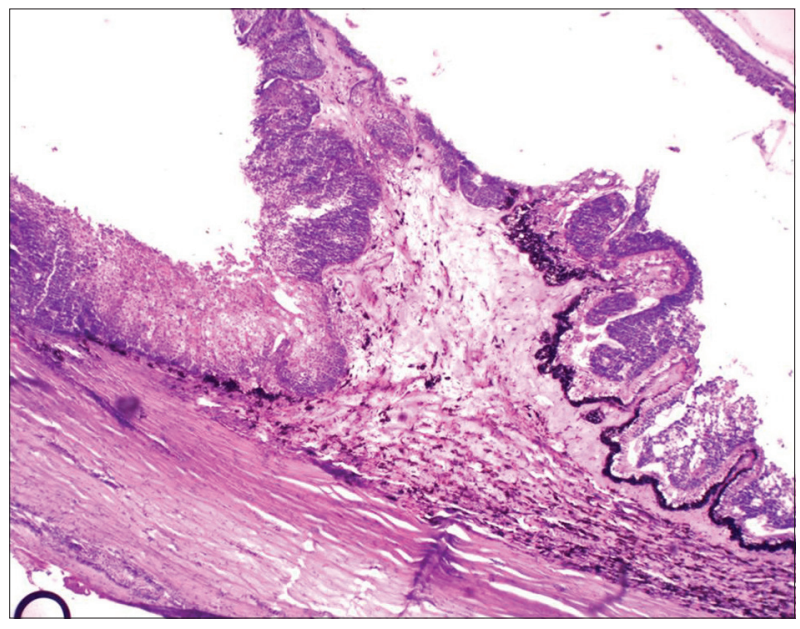

Figure 6: Squamous cell carcinoma infiltrating ciliary processes

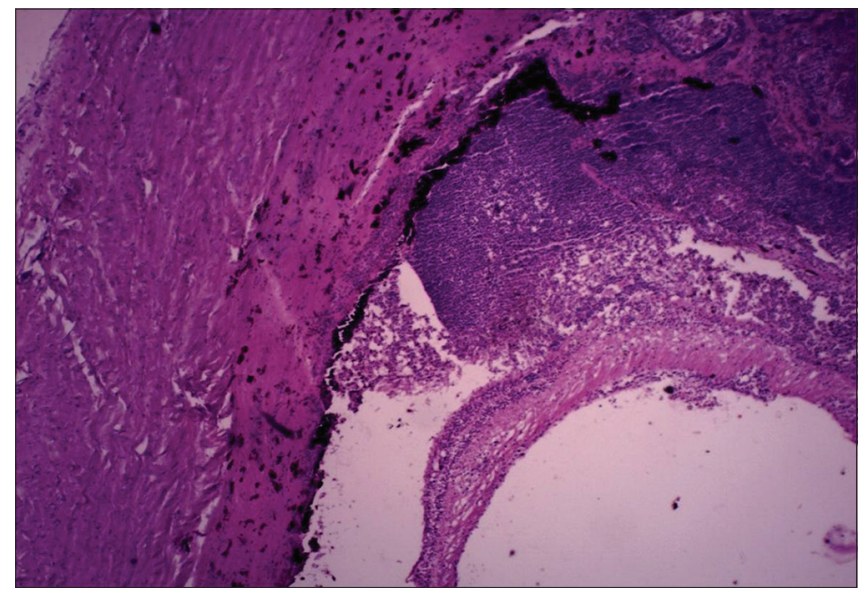

Figure 7: Histopathological examination of the eye showing squamous cell carcinoma invading subretinal space between choroid and retina

different reports from $0.07 \%$ to $2.3 \%$ in patients with advanced generalized malignancy. ${ }^{[2]}$ The most common primary site is breast cancer in $47 \%-49 \%$ of cases and lung cancer in
$14 \%-21 \%$ of cases. The choroid is the most common site for metastasis in the eyes, with uveal metastasis (88\%) where $9 \%$ locate in the iris and $2 \%$ in the ciliary body. ${ }^{[3]}$ However, uveal tissue involvement from gynecological malignancies is extremely rare.

Normally, cervical cancer metastasis occurs through local invasion of surrounding tissue and through lymphatic dissemination. Hematogenous dissemination, although uncommon, is most likely to involve the liver, bones, or lungs. ${ }^{[4]}$ It seems that the high vascularity of the uvea and specifically of the choroid predisposes the eye to intraocular metastases. Presumably, the case discussed above represent a rare instance of hematogenous dissemination to the anterior uveal tissue.

Patients with cancer metastasis to the ciliary body and angle structures usually have associated injected epibulbar vessels and anterior uveitis. An iris metastasis is typically a yellow, gelatinous mass located within the iris stroma. Rarely, the iris tumor may be friable and may seed into the aqueous, producing a pseudohypopyon composed of tumor cells. Other associated findings in those eyes with metastasis to the anterior uvea include ocular hypertension, hyphema, uveitis, rubeosis, cataract, and infiltration into the surrounding structures. In our case, the patient presented as full chamber pseudohypopyon with hyphema and deep vascularization in the inferior quadrant of the cornea and exudates in the vitreous which may be due to metastatic infiltration in the anterior segment of the eye, i.e., iris, ciliary body, and angle structures.

Pseudohypopyon with/without hyphema can also be seen with iris lymphoma ${ }^{[5]}$ In a review of 14 eyes of 13 cases, four cases (4/14) had tumor-induced pseudohypopyon and 7 cases had hyphema. Twelve cases with adequate view of the iris details, clinically detectable iris thickening, or visible mass were noticed in all cases (12/12).

On review of the literature, five cases of carcinoma cervix with uveal tissue metastasis have been reported. Four cases had metastasis to choroid, two were adenocarcinoma, ${ }^{[6,7]}$ two cases were of squamous cell carcinoma, ${ }^{[8,9]}$ and one case was squamous cell carcinoma with metastasis to the iris. ${ }^{[10]}$

The treatment is prescribed to the patients with symptomatic disease and a tumor that threatens visual acuity. The most common treatment remained external beam radiation or plaque radiation over a short period of time. In case of painful blind eyes, enucleation may be considered. In our case, the patient remained asymptomatic after enucleation. 


\section{CONCLUSION}

The case demonstrates that carcinoma cervix can metastasize to unusual but possible site like anterior uvea and can present as pseudohypopyon with or without hyphema. There is a need for suspicion and prompt investigation in a patient with visual complaints and history of primary carcinoma of the cervix. Radiotherapy, chemotherapy, and enucleation may also be considered; however, the finding of uveal metastasis is itself an ominous sign.

\section{Declaration of patient consent}

The authors certify that they have obtained all appropriate patient consent forms. In the form the patient(s) has/have given his/her/their consent for his/her/their images and other clinical information to be reported in the journal. The patients understand that their names and initials will not be published and due efforts will be made to conceal their identity, but anonymity cannot be guaranteed.

Financial support and sponsorship

Nil.

Conflicts of interest

There are no conflicts of interest.

\section{REFERENCES}

1. Ferlay J, Shin HR, Bray F, Forman D, Mathers C, Parkin DM, et al. Estimates of worldwide burden of cancer in 2008: GLOBOCAN 2008. Int J Cancer 2010;127:2893-917.

2. Albert DM, Rubenstein RA, Scheie HG. Tumor metastasis to the eye. I. Incidence in 213 adult patients with generalized malignancy. Am J Ophthalmol 1967;63:723-6.

3. Shields CL, Shields JA, Gross NE, Schwartz GP, Lally SE. Survey of 520 eyes with uveal metastases. Ophthalmology 1997;104:1265-76.

4. Monk BJ, Tewari KS. Invasive cervical cancer. In: DiSaia PJ, Creasman WT, editors. Clinical Gynecologic Oncology. $7^{\text {th }}$ ed. Philadelphia, PA: Mosby; 2007. p. 63-4.

5. Mashayekhi A, Shields CL, Shields JA. Iris involvement by lymphoma: A review of 13 cases. Clin Exp Ophthalmol 2013;41:19-26.

6. Nair AG, Asnani HT, Mehta VC, Mehta SV, Pathak RS. Metastatic adenocarcinoma of the cervix presenting as a choroidal mass: A case report and review of literature of cervical metastases to the eye. Indian J Ophthalmol 2015;63:674-8.

7. Wiegel T, Kleineidam M, Schilling A. Choroid metastasis in a patient with adenocarcinoma of the cervix. A case report. Strahlenther Onkol 1995;171:539-42.

8. Shibeeb O, Athanasiov P, Simon S, Gilhotra J. Cervical carcinoma manifesting as progressive bilateral visual loss. Case Rep Ophthalmol Med 2014;2014:757261.

9. Inoue K, Numaga J, Kaji Y, Toda J, Kato S, Sakurai M, et al. Bilateral choroidal metastases secondary to uterocervical carcinoma of the squamous cell type. Am J Ophthalmol 2000;130:682-4.

10. Kurosawa A, Sawaguchi S. Iris metastasis from squamous cell carcinoma of the uterine cervix. Case report. Arch Ophthalmol 1987;105:618. 